\title{
RADIO FREQUENCY INTERFERENCE (RFI) PRODUCTS ON THE AQUARIUS WEBSITE
}

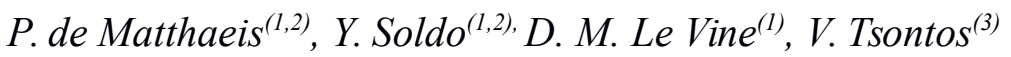 \\ (1) NASA Goddard Space Flight Center, Greenbelt, MD, USA \\ (2) Universities Space Research Association, Columbia, MD, USA \\ (3) NASA JPL, Pasadena, CA, USA
}

\begin{abstract}
Aquarius has produced maps of salinity by measuring Earth's natural emissions at L-band. However, measurements made by its instruments are affected by the presence of Radio Frequency Interference (RFI). For this reason, RFI detection algorithms had been implemented, both for the radiometer and the scatterometer, in order to reduce the impact of RFI on science data. In an effort to improve understanding of L-band RFI, the Aquarius mission has generated a new series of products. This contribution presents how these products were produced as well as the information that they contain. These products will be available starting at the end of January 2018 on the Aquarius website.
\end{abstract}

Index Terms - Aquarius, Radio Frequency Interference.

\section{INTRODUCTION}

Aquarius [1] consists of three L-band radiometers operating in the 1400-1427 GHz band allocated to Earth Exploration Satellite Service (EESS) and an L-band scatterometer operating at $1.26 \mathrm{GHz}$, in a frequency band shared with radiolocation radar systems. As reported in [2] and [3], both instruments experience RFI. The interference in the passive band was first observed by the European Space Agency's Soil Moisture Ocean Salinity (SMOS) mission [4],[5], which has now made some RFI products publicly available in the form of list of sources (RFILST) and data files containing RFI percentages (DGGRFI) [6]. In its final data release, the Aquarius mission is also making its RFI data more readily available with the goal of improving understanding of RFI and of increasing awareness of this problem.

\section{RFI DETECTION ALGORITHMS}

The radiometer RFI detection algorithm identifies individual samples of the antenna temperature that deviate significantly from the average value of nearby samples. Mitigation is accomplished in subsequent processing steps by excluding corrupted samples before averaging them to yield the RFIfiltered antenna temperatures. This algorithm is performed independently for each radiometer channel.

RFI detection for the Aquarius scatterometer is accomplished using a combination of on-board and groundbased processing [3]. The ground-based RFI detection technique is an outlier detection algorithm similar to that employed for the radiometer.

The amount of RFI for a particular data point is quantified using the percentage of detected RFI, defined as the fraction of acquired elementary antenna samples that are flagged as corrupted by RFI within the data point averaging window, expressed in $\%$.

\section{RFI MAPS}

The flags produced by the RFI detection has been used to generate maps of RFI. The most recent version of the radiometer RFI maps have included an RFI flag based on fixed thresholds applied to the antenna temperature [7]. This flag is not used to remove samples from further processing, but, in generating the radiometer RFI data, 100\% RFI is assigned to points where this flag is raised. Examples of these maps are given in the figures below.

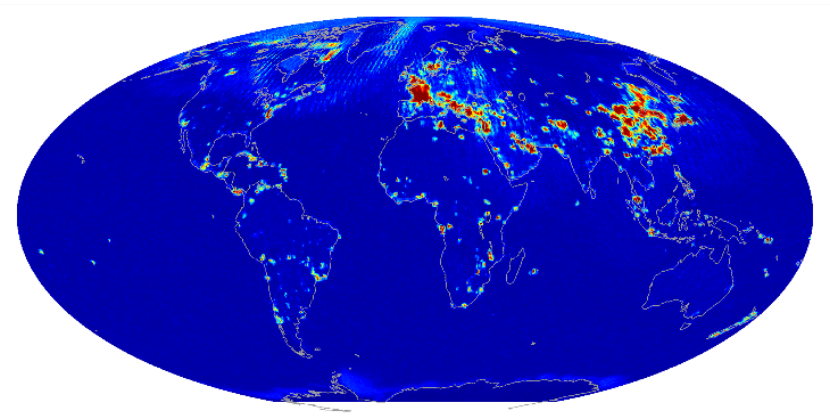

Figure 1: RFI percent for the Aquarius radiometers (all three beams; ascending and descending passes) for January 2013. 


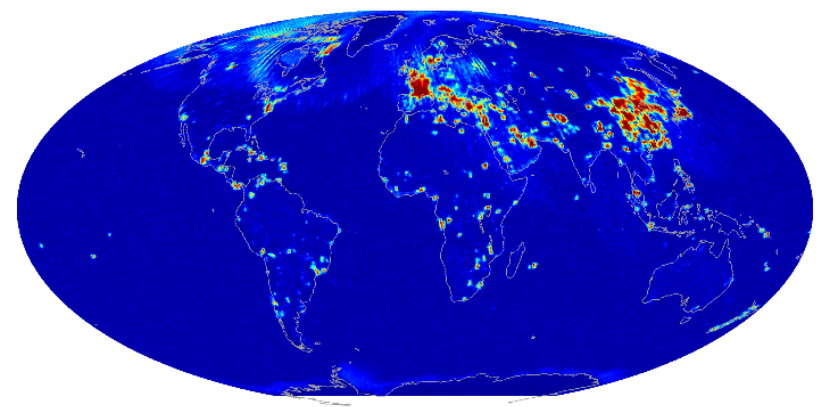

Figure 2: RFI percent for the Aquarius radiometers (all three beams; ascending passes only) for January 2013.

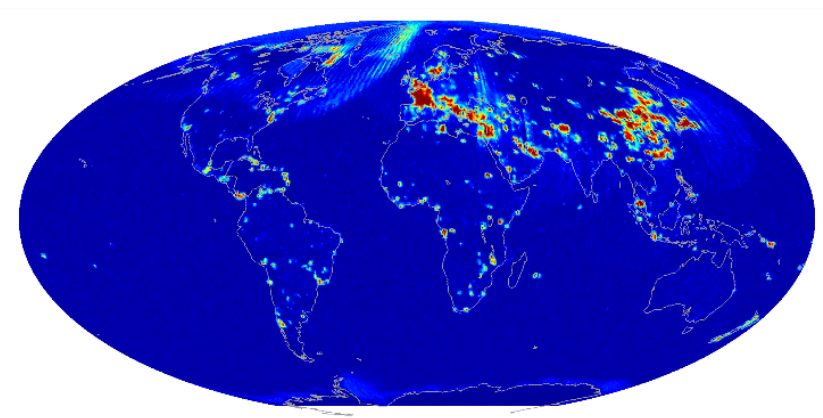

Figure 3: RFI percent for the Aquarius radiometers (all three beams; descending passes only) for January 2013.

Figures 1-3 show the RFI percent of the Aquarius radiometers (i.e., the percentage of samples flagged as RFI by the algorithm in Section 2) for January 2013. These maps include data from all three Aquarius radiometers; however, Figure 1 combines both ascending and descending passes, Figure 2 includes only ascending passes and Figure 3 only descending passes. Note how, for example, the light blue area over Iceland in Figure 1 is almost exclusively due to RFI contamination during the descending passes (Figure 3).

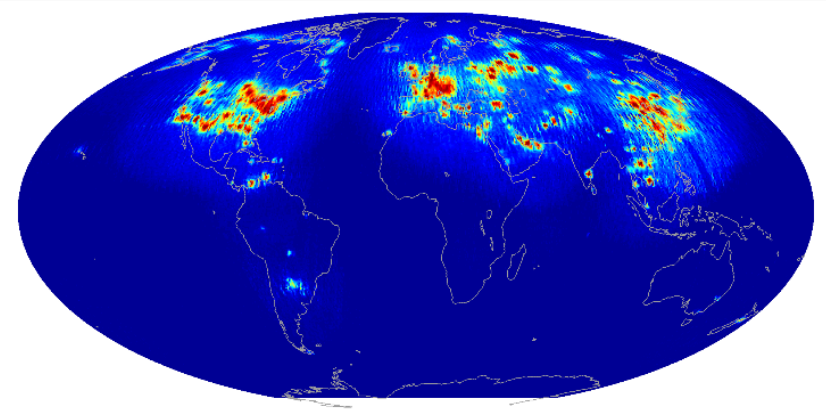

Figure 4: RFI percent for the Aquarius scatterometers (all three beams; ascending and descending passes) for January 2013.
Figure 4 shows the RFI percent for the Aquarius scatterometers (all beams, both ascending and descending passes).

These RFI maps are consistent with those produced by the SMOS mission in and are available on the Aquarius website hosted by the University of Maine ([9] for the radiometer, and [10] for the scatterometer) and are reproducible using the Aquarius RFI products described in the next section.

\section{RFI PRODUCTS}

The monthly-averaged Radio Frequency Interference (RFI) values for ascending/descending passes as detected by the Aquarius radiometers and scatterometers are stored in Hierarchical Data Format (HDF) files on a $0.5 \times 0.5$ degree latitude-longitude grid. The data are available for either ascending (northward) or descending (southward) passes of the satellite only and for ascending/descending passes combined.

This product contains information about RFI, but it is also relevant for the retrieved Sea Surface Salinity (SSS). Over the ocean, the RFI percentage in this product corresponds to the amount of raw measurements discarded due to RFI contamination before SSS retrieval. Therefore, maps of the RFI percentage can give the user an indication of where RFI is more likely to have affected the quality of SSS retrievals, for a particular month.

This product can be used to re-create the RFI maps mentioned in the previous section. Additionally, a user can generate maps by using only a particular beam or only ascending passes, for example. All combinations of beams and ascending/descending passes are possible.

\section{REFERENCES}

[1] D. M. Le Vine, G. S. Lagerloef, F. R. Colomb, S. H. Yueh and F. A. Pellerano, "Aquarius: An instrument to monitor sea surface salinity from space, "IEEE Transactions on Geoscience and Remote Sensing, vol. 45, n.7, pp.2040-2050, 2007

[2] D. M. Le Vine, P. de Matthaeis, C. S. Ruf, and D. D. Chen, "Aquarius RFI detection and mitigation algorithm: Assessment and examples," IEEE Transactions on Geoscience and Remote Sensing 52, no. 8, pp. 4574-4584, 2014.

[3] D. Le Vine and P. de Matthaeis, "Aquarius Active/Passive RFI Environment at L-band, "IEEE Geoscience Remote Letters, vol. 11, n.10, pp. 1747-1751, 2014. 
[4] Y. H. Kerr, P. Waldteufel, J.-P. Wigneron, J. A. M. J. Martinuzzi, J. Font and M. Berger, M., "Soil moisture retrieval from space: The Soil Moisture and Ocean Salinity (SMOS)

[5] SMOS Project: Algorithm Theoretical Basis Document (ATBD) for the SMOS Level 2 Soil Moisture Processor

Development Continuation Project, issue 3.10, 2017.

[6] ftp://smos-diss.eo.esa.int/SMOS/AUX_Dynamic/

[7] Y. Soldo, D. M. Le Vine, P. de Matthaeis and P. Richaume, "L-Band RFI Detected by SMOS and Aquarius, " IEEE

Transactions on Geoscience and Remote Sensing, vol. 55, n. 7, pp. 4220-4235, 2017.
[8] http://www.cesbio.ups-tlse.fr/SMOS_blog/smos_rfi/

[9] https://aquarius.umaine.edu/cgi/gal_radiometer.htm

[10] https://aquarius.umaine.edu/cgi/gal_scatterometer.htm 